\title{
Comparison of Different Methods for Microencapsulation of Probiotics
}

\author{
JUtTA BREITENBACH ${ }^{1, *}$, CHRISTOPHER BEERMANN ${ }^{1}$, GÜNTER J. ESPER ${ }^{1}$
}

\begin{abstract}
At the Department of Food Technology at Fulda University of Applied Sciences different methods for microencapsulation of Lactobacillus reuteri DSM 20016 were investigated. The aim of these studies was to develop a process to stabilize the probiotic bacteria for storage and to prevent them from the gastric conditions, to ensure that a satisfactory amount of the probiotics could reach their target location, the human intestine. Drying processes like spray drying and freeze drying were tested as well as fluidized bed granulation with optional Wurster coating using different auxiliary materials. As encapsulation material maltodextrine, sweet whey powder or gummi arabicum were used. The coating experiments were performed with an aqueous shellac solution.

In the performed studies the fluidized bed bottom spray granulation with an additional Wurster coating turned out to be an encouraging procedure to keep the probiotics in a stable form resistant against gastric conditions. The survival rate in the simulated gastro-intestinal passage could be increased up to the sevenfold amount of the untreated bacteria.
\end{abstract}

Keywords: fluidized bed granulation, Wurster coating, spray drying, freeze drying, Lactobacillus reuteri

\section{Introduction}

Probiotic microorganisms play a major role in today's nutrition. The World Health Organization (WHO) and the Food and Agriculture Organization of the United Nations (FAO) define probiotics as "Live microorganisms which when administered in adequate amounts confer a health benefit on the host" (FAO/WHO 2001). Various health benefits, for example on disorders relating to the gastro intestinal tract, are reported on the consumption of different probiotics. The report "Health and Nutrition Properties of Probiotics in Food including Powder Milk with Live Lactic Acid Bacteria" from FAO/WHO Expert Consultation 2001 gives an extensive overview about the properties of probiotics to the human health (FAO/WHO 2001).

\footnotetext{
*Corresponding author. E-mail: jutta.breitenbach@lt.hs-fulda.de

${ }^{1}$ Fulda University of Applied Sciences, Department of Food Technology, Fulda, Germany
} 
To get a healthy effect on the consumer of probiotic food, the concentration of the viable microorganisms has to be in a sufficient range. Therefore it is a great challenge to bring the probiotics into a stable form, which guarantees, that the microorganisms reach their target location, the human intestine, in a satisfactory amount. This issue includes on the one hand the problem of storage of the probiotic material itself as well as the storage of the probiotic foodstuff and on the other hand the time-released utilization in the gastrointestinal passage. For use in foods, probiotic microorganisms should not only be capable of surviving passage through the digestive tract but also have the capability to proliferate in the gut. This means they must be resistant to gastric juices and be able to grow in the presence of bile under conditions in the intestines, or be consumed in a food vehicle that allows them to survive passage through the stomach and exposure to bile. They are Gram positive bacteria and are included primarily in two genera, Lactobacillus and Bifidobacterium (FAO/WHO 2001, Holzapfel et al. 1998; Klein et al. 1998).

Microencapsulation is a suitable technology to prevent the microorganisms from the harmful conditions in the human gastro-intestinal tract and to allow them to develop their healthy effect in the human gut. Various microencapsulation techniques for a broad range of probiotics have been reported. Chávarri et al. and Himanshu et al. (2013) give a detailed review about methods for microencapsulation like extrusion or emulsion techniques as well as drying processes (fluidized bed drying, spray drying or freeze drying) or granulation processes with several carrier materials such as starch, skim milk, alginate, gummi arabicum, k-carrageenan, chitosan. To protect the probiotic bacteria from thermal injury during the drying process trehalose or sorbitol could be added to the cell suspension as heat protectant (Wassermann et al. 2011) or protection against cold (Azim et al. 2012).

So the aim of different studies, carried out at the Department of Food Technology of the Fulda University of Applied Sciences, was to develop a microencapsulation process for Lactobacillus reuteri with an additional coating process to prevent the probiotic microorganisms from the hostile conditions during storage and consumption.

\section{Materials and Methods}

The studies were performed on Lactobacillus reuteri DSM 20016, a probiotic lactic acid bacterium. After (pre-) cultivation of the L. reuteri in shaking flask batch slurry fermentation in de Man-Rogosa-Sharpe (MRS) broth the 
bacteria were dried in different drying processes and with different additives. Spray-drying processes were conducted with maltodextrine (MD), gummi arabicum (GA) or sweet whey as encapsulation material for the microorganisms. With two of these substrates (MD and GA) freeze drying processes were performed, too. In comparison to these straight drying processes for encapsulation of the L. reuteri a granulation process, operated in a fluidized bed granulator with bottom spray, was the topic of additional studies. As encapsulation material here maltodextrine or sweet whey powder was used. Furthermore the received granules were coated in a Wurster process with shellac to improve the resistance against the gastric conditions. Also in a fluidized bed granulation process, but with top spray mode, different additives for the protection of the bacteria against thermal stress during the granulation were investigated. The amount of viable cells in the obtained powders, granules and coated granules as well as in the original fermented slurry, specified in colony forming units per gram (CFU/g) or colony forming units per milliliter $(\mathrm{CFU} / \mathrm{ml})$, was evaluated by pour plate count method. Based on these bacterial counts the survival rates for Lactobacillus reuteri during the drying, granulation and coating processes and the storage periods could be determined.

The relative viability of the $L$. reuteri after the process was calculated as the bacterial survival rate by the following equation (1) (Schell, D.; Beermann, C. 2014, Nagy, Ádám György 2015):

where

$$
\mathrm{SR}=\frac{\mathrm{C} 1 * \mathrm{~m} 1}{\mathrm{C} 0 * \mathrm{~V} 0} * 100
$$

(Nagy, Ádám György 2015)

The conversion rate of the bacteria describes the relation between the bacteria amounts in the dried product and the bacteria slurry, see equation (2) (Nagy, Ádám György 2015).

$$
\mathrm{CR}=\frac{\mathrm{C} 1}{\mathrm{C} 0} * 100
$$

(Nagy, Ádám György 2015) 
where

$\mathrm{CR}[\%] \quad=$ bacterial conversion rate of the process

$\mathrm{C} 1\left[\mathrm{CFU}^{*} \mathrm{~g}^{-1}\right] \quad=$ viable cell concentration of the product

$\mathrm{C} 0\left[\mathrm{CFU}^{*} \mathrm{~mL}^{-1}\right]=$ viable cell concentration of the slurry

Additionally in this way the amount of viable cells during the simulated gastrointestinal passage and with it the survival and release rate under gastrointestinal conditions was evaluated.

\subsection{Lactobacillus reuteri}

Lactobacillus reuteri is a natural inhabitant of the gastro-intestinal tract of mammals and birds. L. reuteri are gram-positive, rod-shaped, heterofermentative lactic acid bacteria. Optimal growth temperature of these anaerob but aerotolerant bacteria is between $30-40(45){ }^{\circ} \mathrm{C}$ at a $\mathrm{pH}-$ value of $5-6$. The lethal temperature is reached with $65^{\circ} \mathrm{C}$ (sub-lethal range 50 - 52 ${ }^{\circ} \mathrm{C}$ ) (Kandler O.; Stetter K.; Kohl R. 1980, Reuter G. 1965).

The bacterial strain Lactobacillus reuteri DSM 20016, used for the performed studies, was obtained from Leibniz-Institut DSMZ-German Collection of Microorganisms and Cell Cultures $\mathrm{GmbH}$, Braunschweig, Germany.

\subsection{Encapsulation materials}

The following substances were used as encapsulation materials: - Spray dried Maltodextrine (DE19) from different suppliers; - Gummi Arabicum powder, spray dried, from Carl Roth GmbH \& Co. KG, Karlsruhe, Germany; - Spray dried Sweet Whey Powder Bayolan ${ }^{\circledR}$ from Bayerische Milchindustrie eG, Landshut, Germany

\subsection{Coating material}

For the coating processes $\mathrm{SSB} \circledast$ Aquagold (from Stroever $\mathrm{GmbH} \& \mathrm{Co}$. KG, Bremen, Germany), an aqueous shellac solution $(25 \%(w / w))$, was used. 


\subsection{Spray drying}

Spray drying is a convective drying process which allows the removing of humidity (solvent, dispersion agent) in one single step. The principle of spray drying is to divide the liquid phase into very small droplets by using suitable atomization devices. This generates a big surface for heat and mass transfer with the drying air. Although high temperatures for the drying air are recommended spray drying is a gentle drying method because of the very short process time.

\subsection{Freeze drying}

Freeze drying is a drying procedure which removes the humidity out of the frozen state of the product by using vacuum. The drying takes place at pressures and temperatures below the triple point of the solvent. So this method is suitable for temperature sensitive products.

\subsection{Fluidized bed granulation}

The liquid product (solution, suspension, dispersion) is directly sprayed into a fluidized bed of the carrier material. This encapsulation material is fluidized by (warm) air, which flows through the material from bottom to top. The injection of the liquid by using a two-phase nozzle could take place in the bottom of the fluidized bed or on top of the fluidized bed.

\subsection{Wurster coating}

A circulating fluidized bed could be generated by the use of a Wurster tube within a fluidized bed granulator. By spraying (bottom spray) a liquid coating material (solution or molten mass) into this circulating fluidized bed the particles could be covered with a homogeneous layer out of the coating material. 


\section{Results}

\subsection{Encapsulation}

Spray drying is one of the straight drying processes which were investigated for the encapsulation of the microorganisms. Several additives in different concentrations were tested as encapsulation material for the Lactobacillus reuteri. The spray drying experiments were executed on a Büchi 190 Mini Spray Dryer (BÜCHI Labortechnik GmbH, Essen, Germany). The bacteria culture of Lactobacillus reuteri was suspended in a solution/suspension of maltodextrine (10 or $20 \%$ ) on the one hand and a solution/suspension of gummi arabicum (5 or 10\%) on the other hand. With an inlet temperature of $87^{\circ} \mathrm{C}$ and the outlet temperature of $55^{\circ} \mathrm{C}$ for the drying air a survival of the $L$. reuteri could be observed. The bacteria survival rate describes the relation between the amounts of viable cells in the bacteria slurry before the drying and in the rehydrated dry product; the concentration of the dry product in this suspension for determination of the viable cell numbers correspond to the solid content in the bacteria slurry before the drying. The survival rates ranged between 40 and $90 \%$ for the maltodextrine as carrier material and between 20 and 50\% for the gummi arabicum, Figs 1 and 2. With an increasing outlet temperature up to $62^{\circ} \mathrm{C}$ (combined with increasing inlet temperature up to $100^{\circ} \mathrm{C}$ ) of the drying air the survival rates decreased significantly down to $4 \%$ for MD $(10 \%)$ as encapsulation material (Szántó, Viola 2013).

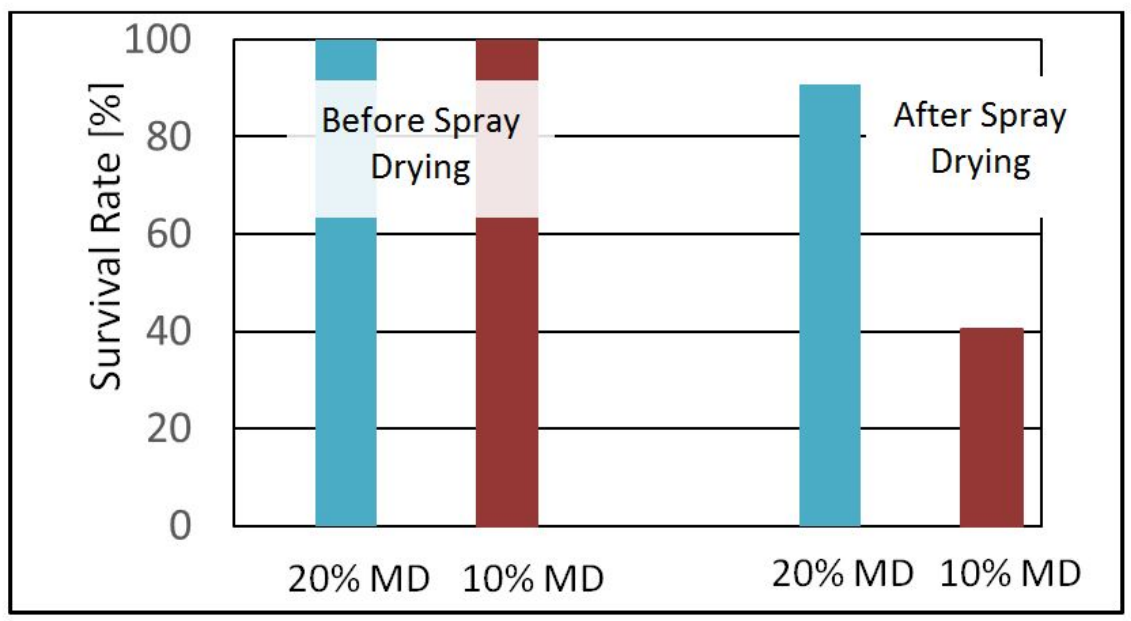

Fig. 1. Bacteria survival rates before and after spray drying with 10 and $20 \%$ maltodextrine (MD) as encapsulation material (Szántó, Viola 2013) 


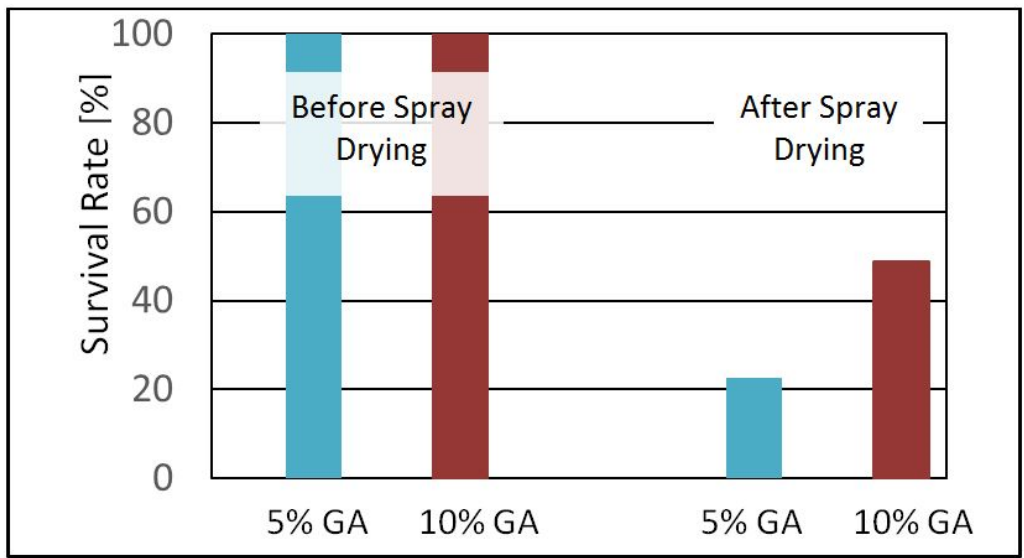

Fig. 2. Bacteria survival rates before and after spray drying with 5 and $10 \%$ gummi arabicum (GA) as encapsulation material (Szántó, Viola 2013)

Furthermore a slurry of $L$ reuteri, fermented in $20 \%$ sweet whey solution with $0.5 \%$ yeast extract as supplement, was dried directly in the Büchi 190 Mini Spray Dryer, too. Independent of the outlet temperature

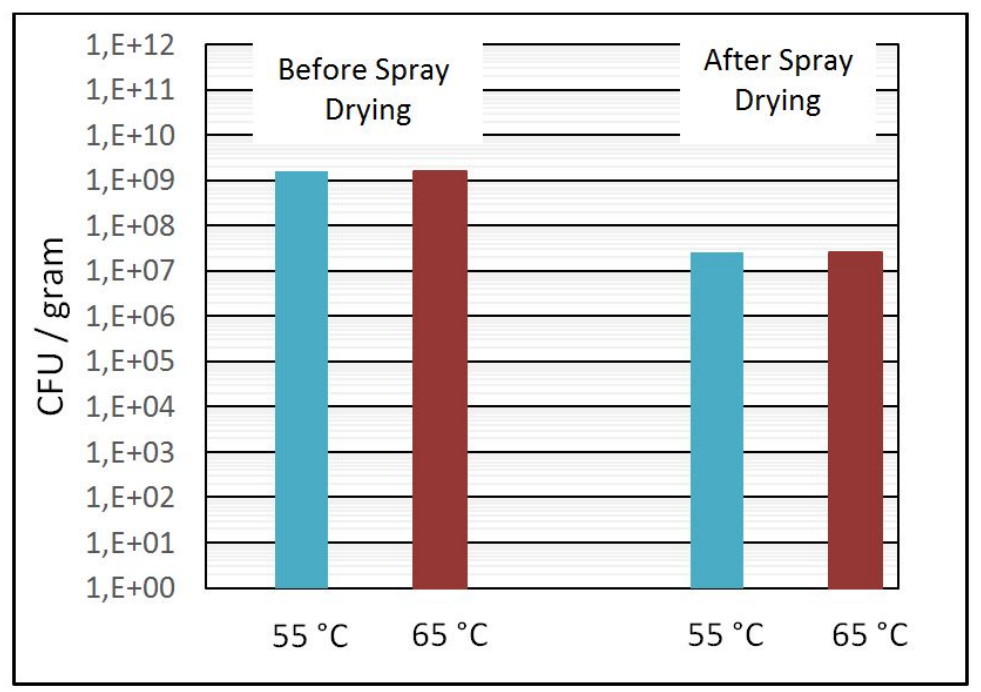

Fig. 3. Cell counts of L. reuteri before and after spray drying process with $55^{\circ} \mathrm{C}$ and $65^{\circ} \mathrm{C}$ outlet temperature, directly from slurry-fermentation in whey $20 \%(w / v)$ with $0.5 \%(w / v)$ yeast extract supplementation. The data shown represents the mean of at least 3 measurements (Jantzen, M.; Göpel, A.; Beermann, C. 2013). 
$\left(55^{\circ} \mathrm{C}\right.$ and $\left.65^{\circ} \mathrm{C}\right)$ of the drying air the numbers of bacteria decreased about two orders of magnitude, see Fig. 3. Before the determination of the viable cell amount of the spray dried product, this was rehydrated at a solid content of $20 \%(w / v)$, according to the solid content in the spraying slurry (Jantzen, M.; Göpel, A.; Beermann, C. 2013). This decreasing of viable cells during the spray drying process comes up to a survival rate of approximately $1.5 \%$. But nevertheless the total number of viable cells after the spray drying process is still within a satisfactory range.

The second straight drying process which was examined was the freeze drying. The tests were carried out in a freeze dryer Beta 2-16 (Martin Christ Gefriertrocknungsanlagen $\mathrm{GmbH}$, Osterode, Germany).

As encapsulation material maltodextrine and gummi arabicum, each in a concentration of $10 \%$ and $20 \%$, were used. Figures 4 and 5 show the achieved survival rates for the $L$. reuteri in the conducted freeze drying processes. The survival rates were determined as the relation between the cell counts of the slurry to be dried and in the equal solid content rehydrated dry product. The maximum survival rates were $19 \%$ for $10 \%$ MD as additive and $10.7 \%$ for $10 \%$ GA as additive (Szántó, Viola 2013).

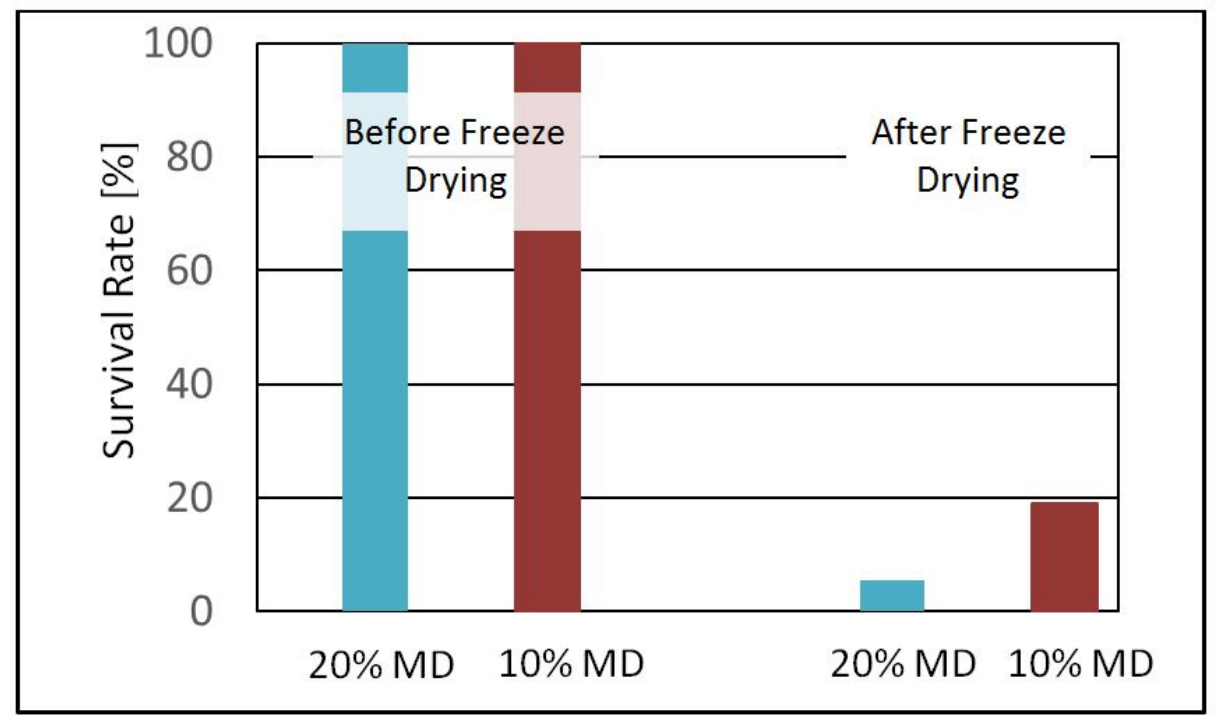

Fig. 4. Survival rates for the L. reuteri after a freeze drying process with 10 or $20 \%$ maltodextrine (MD) as encapsulation material (Szántó, Viola 2013) 


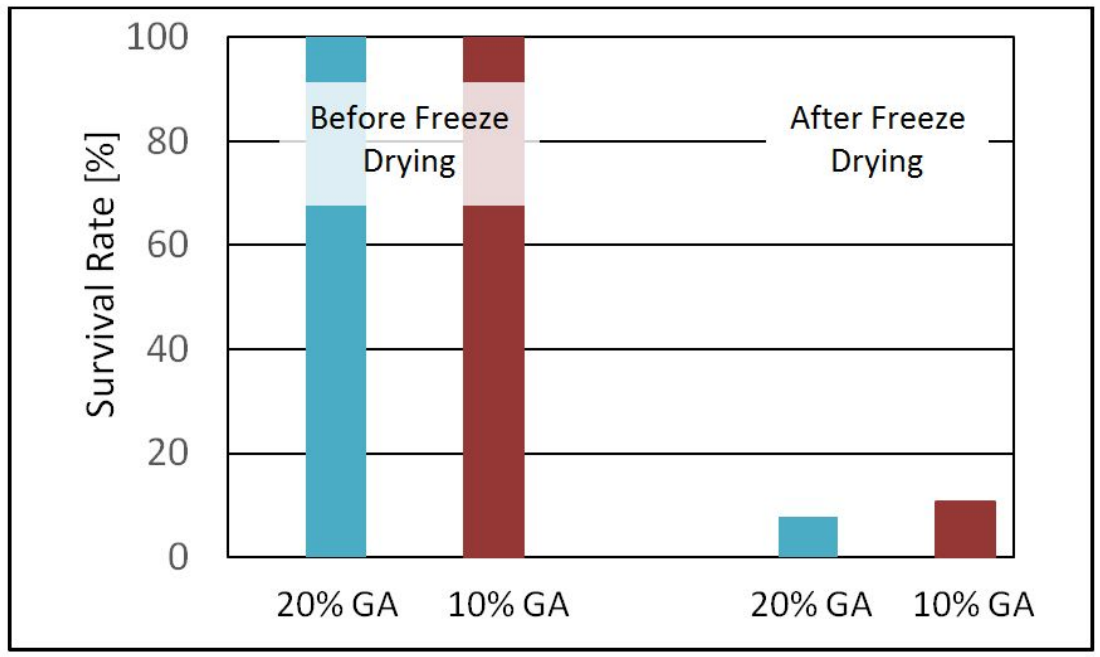

Fig. 5. Survival rates for the L. reuteri after a freeze drying process with 10 or $20 \%$ gummi arabicum (GA) as encapsulation material (Szántó, Viola 2013)

Besides the straight drying processes the fluidized bed granulation process (FBGP) was examined, too. Two different operation methods were investigated, top spray technique on the one hand by using a Midi Glatt fluidized bed granulator (Glatt GmbH, Binzen, Germany) and on the other hand the bottom spray mode by using a Diosna Minilab fluidized bed granulator (Diosna, Diercks \& Söhne GmbH, Osnabrück, Germany). As encapsulation material in these processes maltodextrin was used as well as sweet whey powder. Optionally the granulation process was followed by a coating process with shellac to improve the viability of the dried L. reuteri. In the experiments which were operated with the top spray mode of the FBGP sweet whey powder was used as encapsulation material. The granulation experiments were executed at an inlet temperature for the fluidizing air of $50^{\circ} \mathrm{C}$, with an atomizing pressure of 0.6 bar for 15 minutes process time. Different extra additives, trehalose, sorbitol and maltodextrine, were tested to protect the bacteria from the thermal impact during the granulation process. The effect of a top spray coating with shellac in a second step after the granulation was tested with this experimental setup, too. As shown in Fig. 6, relative viabilities of nearly $43 \%$ could be achieved with trehalose or sorbitol as heat protectant (Schell, D.; Beermann, C. 2014). 


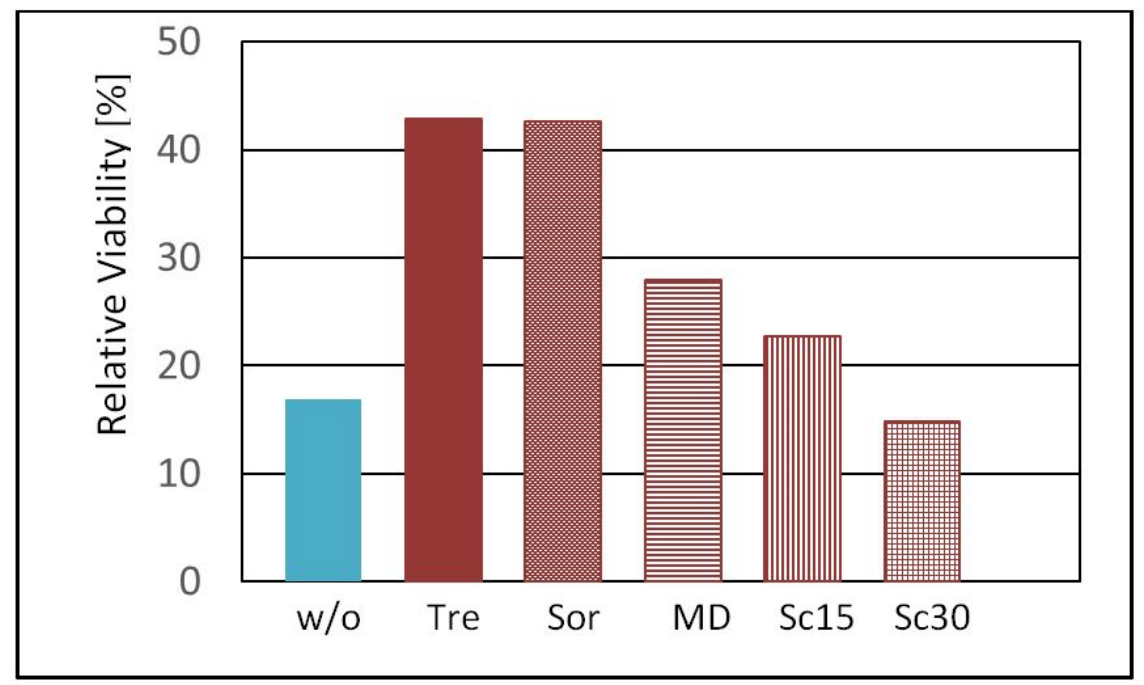

Fig. 6. Observed relative viabilities of L. reuteri in absence $(w / 0)$ and in presence of the thermos-protectants trehalose (Tre), sorbitol (Sor) and maltodextrine (MD) after fluidized bed granulation at $50^{\circ} \mathrm{C}$ for $15 \mathrm{~min}$, as well as top-spray coating with shellac for $15 \mathrm{~min}$ (Sc15) and $30 \mathrm{~min}$ (Sc30) (Schell, D.; Beermann, C. 2014)

Fluidized bed granulation at bottom spray mode allows a more robust process. In this case longer granulation times could be reached. Longer process times enable a higher input of the microorganisms into the generated granules, even if the survival rate itself decreases with increasing process time (Nagy, Ádám György 2015). Bottom spray fluidized bed granulation was performed with maltodextrine as well as with sweet whey powder as encapsulation material. The test series operated with maltodextrine showed additionally to the dependency of the bacteria survival from the process time a dependency from the shear stress of the bacteria slurry, expressed by the atomizing pressure of the slurry, too. Due to a temperature sensitivity of the $L$. reuteri found in preliminary tests the granulations were operated at inlet air temperature of $40^{\circ} \mathrm{C}$. The bacteria survival rate decreases steadily down to about $60 \%$ after a process time of one hour at low shear stress ( 0.25 bar atomizing pressure). On the other hand a decrease of the survival rate for the L. reuteri down to about $30-40 \%$ was found for higher shear stress of the bacteria slurry ( 1 and 2 bar atomizing pressure), Fig. 7 (Nagy, Ádám György 2015). 


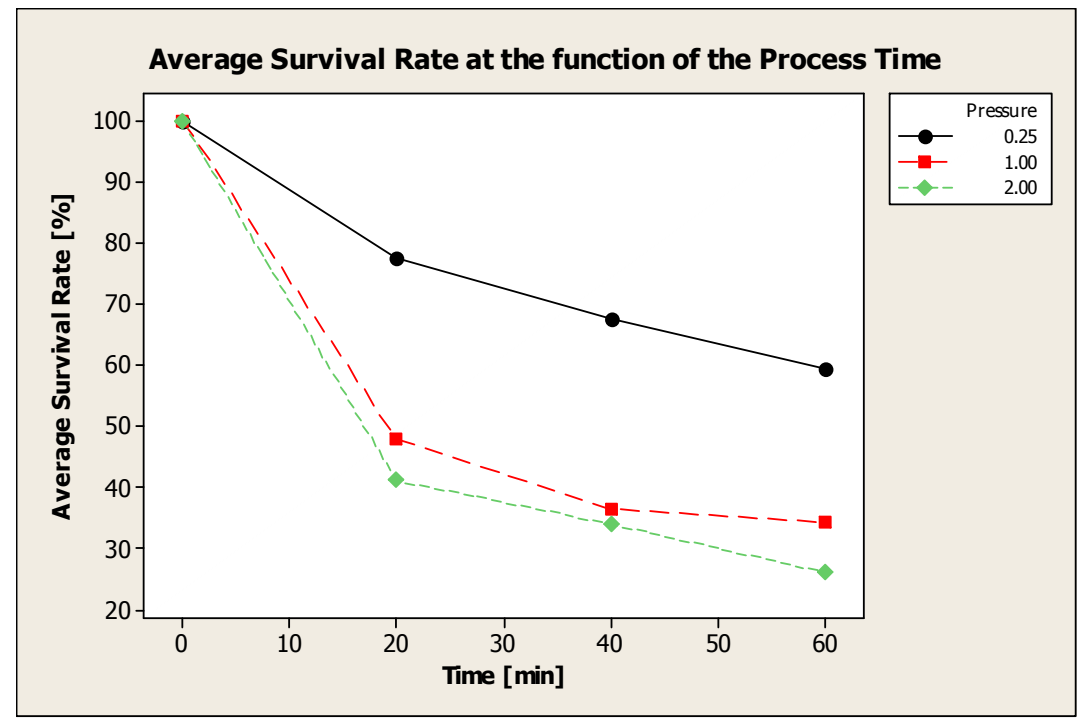

Fig. 7. Average bacterial survival rate as a function of the granulation time with maltodextrine as encapsulation material (Nagy, Ádám György 2015)

In contrast to the straight drying processes the fluidized bed granulation is a batch process in which during the process time continuously more microorganisms could be brought into the product. The decreasing survival rate of the $L$. reuteri with longer granulation times counteracts this advantage. To evaluate the excellence of the process concerning the number of viable microorganisms in the dry product an additional parameter was defined. The conversion rate of the bacteria describes the relation between the bacteria amounts in the dried product and the bacteria slurry (see "materials and methods", equation (2)) (Nagy, Ádám György 2015).

In Fig. 8 these conversion rates are diagrammed for the granulation of $L$. reuteri with maltodextrine as encapsulation material at an inlet air temperature of $40^{\circ} \mathrm{C}$ (compare Fig. 7, corresponding survival rates). The bacteria conversion rates increase with increasing process times up to about $75 \%$ for an atomizing pressure of 0.25 bar (Nagy, Ádám György 2015).

The effect of coating by using a Wurster device with shellac as coating material in a second step after the granulation was tested with this experimental setup, too. Significant differences in the bacterial survival rate before the coating process and after the coating process could not be determined (Nagy, Ádám György 2015). 


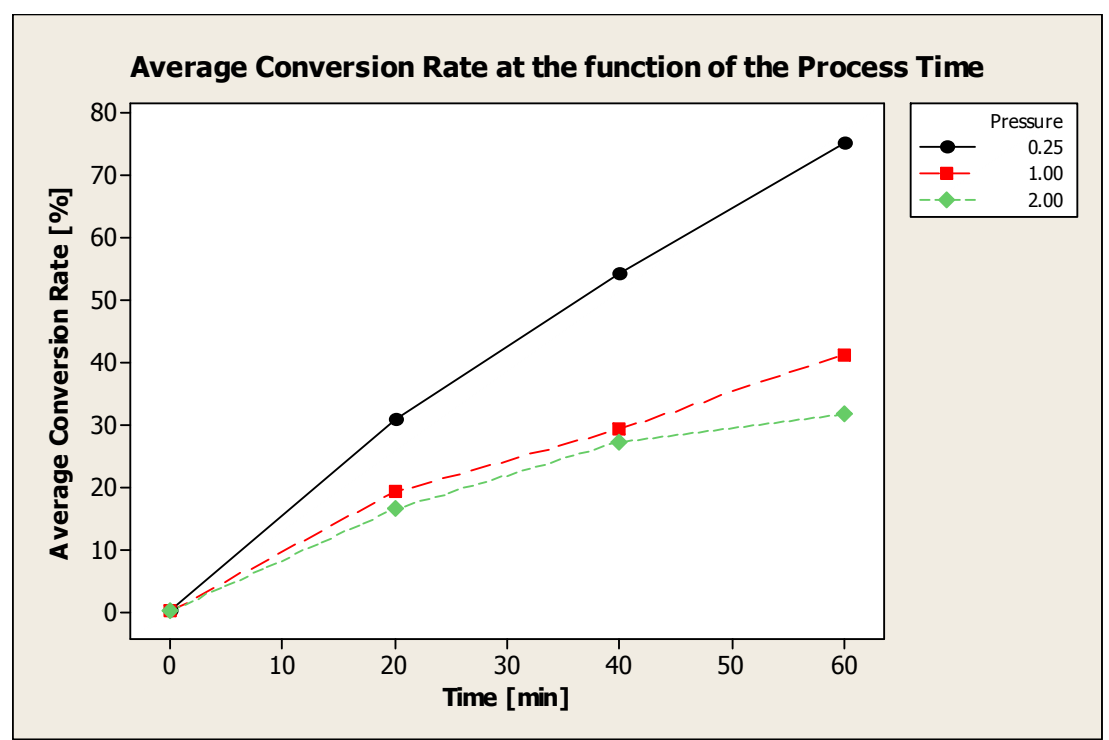

Fig. 8. Average bacterial survival rate as a function of the granulation time with maltodextrine as encapsulation material (Nagy, Ádám György 2015)

In further test series sweet whey powder as encapsulation material was investigated. The experiments were executed with bottom spray fluidized bed granulation followed by a fluidized bed Wurster coating with shellac. A solid granulation process could be achieved, differing to the process with maltodextrine, at an inlet air temperature of $60^{\circ} \mathrm{C}$ and an atomizing pressure of 2 bar. The granulation time was 60 minutes and the coating time was 60 minutes at $60^{\circ} \mathrm{C}$ inlet air temperature and 2 bar atomizing pressure, too. First coating samples were taken after 30 minutes coating time. The survival rates of the $L$. reuteri after every single process step are diagrammed in Fig. 9. After the granulation $(G)$ a survival rate of the bacteria of $38 \%$ was found. The coating reduced the survival rate down to $14 \%$ after 30 minutes (C30) of coating respectively $11 \%$ after 60 minutes (C60) (Markó, Lilian 2015).

The relative viabilities shown in Fig. 9 are based on the numbers of colony forming units per milliliter $(\mathrm{CFU} / \mathrm{ml})$ specified in Table 1 (Markó, Lilian 2015). 


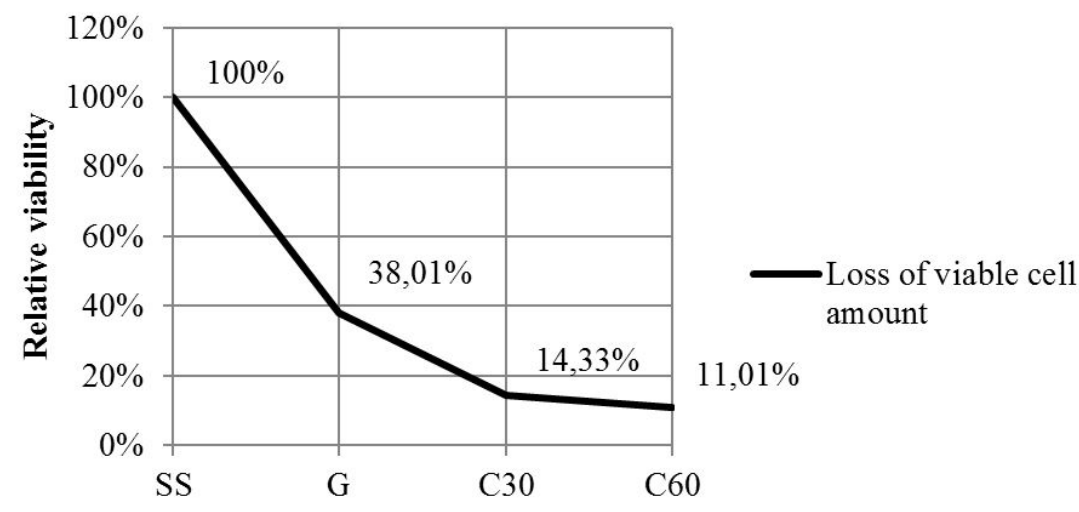

Stages of process

Fig. 9. Relative viability of L.reuteri after different stages of microencapsulation (Markó, Lilian 2015)

Table 1. Characteristic of samples in different process stages (Markó, Lilian 2015)

\begin{tabular}{|c|c|c|c|}
\hline Process & Label & Time $[\mathrm{min}]$ & $\begin{array}{c}\text { Colony forming } \\
\text { unit }[\mathrm{CFU} / \mathrm{mL}]\end{array}$ \\
\hline Bacteria strain preparation & SS & 0 & $1.96^{*} 10^{8} \pm 3.62^{*} 10^{7}$ \\
\hline Granulation & G & 60 & $7.54^{*} 10^{7} \pm 2.57^{*} 10^{7}$ \\
\hline \multirow{2}{*}{ Coating } & C 30 & 30 & $2.94^{*} 10^{7} \pm 1.05^{*} 10^{7}$ \\
\cline { 2 - 4 } & C60 & 60 & $2.21^{*} 10^{7} \pm 8.62^{*} 10^{6}$ \\
\hline
\end{tabular}

\subsection{Behavior under gastric conditions}

The place where the probiotics should develop their positive effects is the human intestine. Therefore the behavior of the microorganisms during the gastrointestinal passage is important for the evaluation of the microencapsulation process for the $L$. reuteri. The microencapsulated product was treated with simulated gastric juice $(\mathrm{pH} 1.9$, containing pepsin) for 30 minutes; then the $\mathrm{pH}$ was adjusted to 7.5 and pancreatin and bile salts were added to simulate the intestine juice. At several times in this process samples were taken and the viable cells and from this the survival rates respectively release rates for the bacteria were determined, according to 
Picot A., Lacroix C. (2004). Figure 10 shows the survival and release rates under gastric/intestinal conditions for L. reuteri, encapsulated with sweet whey powder by spray drying in contrast to not encapsulated bacteria. Under gastric conditions the survival rates drop significantly down to about $10 \%$ for the not encapsulated material and about $25 \%$ for the encapsulated material. In the further progress of the test the release rate for the L. reuteri increases for the encapsulated material to about $50 \%$ while the release rate for the not encapsulated material stays at the low level of about $10 \%$. (Jantzen, M.; Göpel, A.; Beermann, C. 2013)

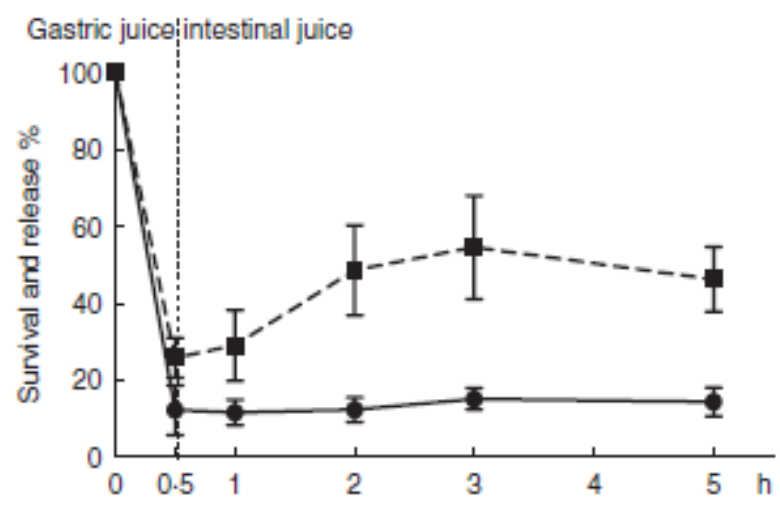

Fig. 10. Percentage release and survival of encapsulated ( $\mathbf{\square})$ and not encapsulated ( $)$ L. reuteri in simulated gastric juice for $30 \mathrm{~min}$ and afterwards in simulated intestinal juice for a maximum of 5 h (Jantzen, M.; Göpel, A.; Beermann, C. 2013)

The L. reuteri dried in a bottom spray fluidized bed granulation process with maltodextrine as encapsulation material show in an in vitro gastrointestinal test a survival rate of approximately $10 \%$ under gastric conditions (see Fig. 11, incubation time half an hour). After the setting up to intestine conditions (increasing $\mathrm{pH}$-value, adding of further digestive enzymes) the number of viable cells and with it the survival/release rate were increasing up to about $200 \%$ maximum with the incubation time. Figure 11 presents this for an atomizing pressure of 0.25 bar and different granulation times (Nagy, Ádám György 2015). 


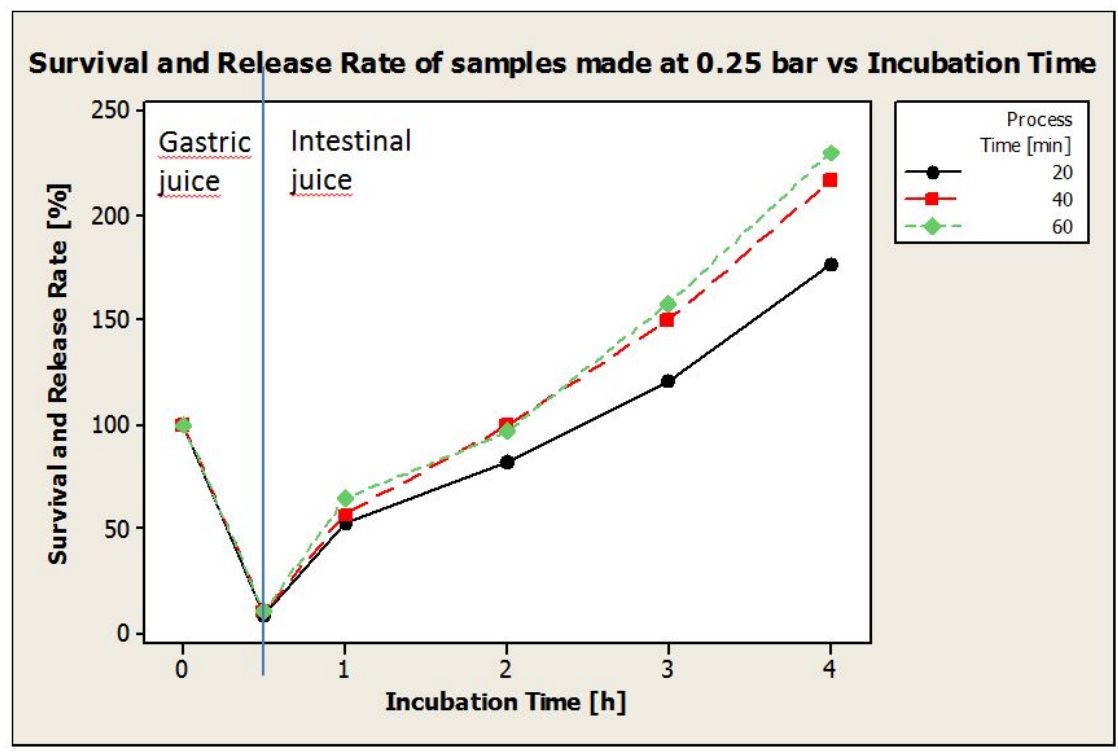

Fig. 11. Survival and release rate of the L. reuteri granulated with maltodextrine at 0.25 bar atomizing pressure during incubation in artificial gastrointestinal conditions (Nagy, Ádám György 2015)

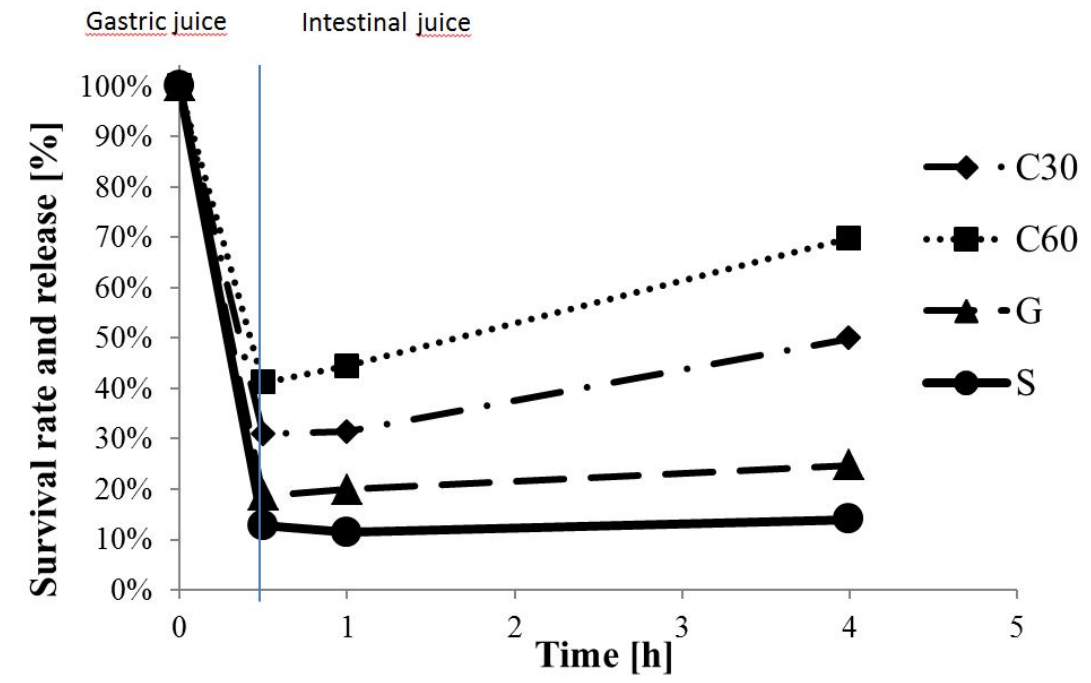

Fig. 12. Survival and release rate of the L. reuteri granulated with sweet whey powder $(\mathrm{G})$ and additionally coated with shellac for 30 minutes (C30) respective 60 minutes (C60) in comparison to not granulated/coated material (S) during incubation in artificial gastrointestinal conditions (Markó, Lilian 2015) 
Bottom spray fluidized bed granulation of the bacteria with sweet whey powder as encapsulation material followed by a wurster coating with shellac effects an increasing of the survival/release rate of the L. reuteri under intestinal conditions, too. After an abrupt drop down after 30 minutes incubation time (according to the gastric conditions) the following intestinal conditions cause for the shellac coated microorganisms a steady rise of the bacteria survival/release rate up to $70 \%$ maximum with the incubation time, diagrammed in Fig. 12 (Markó, Lilian 2015).

\section{Discussion}

In the carried-out studies about microencapsulation of L. reuteri the straight drying processes (spray drying and freeze drying) stood vis-á-vis to the granulation processes in a fluidized bed. In every of these processes it was possible to reach cell numbers of the $L$. reuteri in the dried product, which could be sufficient for causing a healthy effect in the human body, even if the microorganisms have to be protected from the conditions during the gastric passage. Anyway the fluidized bed granulation processes seem to be more appropriate for a technical implementation. On the one hand the temperatures of the drying air in the spray drying process have to be in a very low range, so that an efficient operation appears to be problematic. On the other hand the granulation processes give the opportunity to control the reachable viable cell numbers with the process time.

\section{Conclusions}

The bottom spray fluidized bed granulation process with maltodextrine as encapsulation material followed by an additional coating with shellac in a Wurster process turned out to be a suitable way to bring the L. reuteri into a stable form resistant against gastric conditions. In comparison to the fluidized bed granulation with sweet whey powder lower temperatures for the inlet air temperature could be realized, $40^{\circ} \mathrm{C}$ for maltodextrine compared to $60^{\circ} \mathrm{C}$ for the sweet whey powder. Shellac turned out to be an appropriate coating material, insoluble in the simulated gastric juice, but able to release the $L$. reuteri in the simulated intestinal juice up to the sevenfold in concentration compared to the uncoated bacteria. To reach the target, namely to provide a sufficient amount of viable L. reuteri in the product, which will be released primary in the human intestines, continuing 
studies are actually performed at the Department of Food Technology of the Fulda University of Applied Sciences. One focus of these studies is the improvement of the coating process with the aim to generate a homogenous layer around the particles containing the $L$. reuteri with an adequate thickness and without cracks. So that on the one hand the gastric conditions could not harm the bacteria and on the other hand the time-released utilization of the microorganisms could be enabled in the intestinal environment. Another important topic in the further studies is to increase the resistance of the microorganisms against the elevated temperatures $\left(<60^{\circ} \mathrm{C}\right)$ during the encapsulation processes.

\section{References}

Azim, H.; Kalavathy, R.; Julianto, T.; Sieo, C.; Wan Ho, Y. (2012) “Effect of Heat, pH and Coating Process with Stearic Acid Using a Fluidized Bed Granulator on Viability of Probiotic Lactobacillus reuteri C 10" in African Journal of Biotechnology 11 (2012), pp. 6857-6865.

Chávarri, M.; Marañón, I.; Villarán M., C. "Encapsulation Technology to Protect Probiotic Bacteria", Chapter 23, Bioprocesses \& Preservation Area, Health Division, Tecnalia, Parque Tecnológico de Álava, Miñano (Álava), Spain.

FAO and WHO (2001) "Health and Nutrition Properties of Probiotics in Food including Powder Milk with Live Lactic Acid Bacteria" a Report of a Joint FAO/WHO Expert Consultation on Evaluation of Health and Nutritional Properties of Probiotics in Food including Powder Milk with Live Lactic Acid Bacteria, Cordoba, Argentina, 1-4 October 2001.

Himanshu, K. Solanki; Dipak D. Pawar; Dushyant A. Shah; Vipul D. Prajapati; Girish K. Jani; Akil M. Mulla; and Prachi M. Thakar (2013) "Development of Microencapsulation Delivery System for Long-Term Preservation of Probiotics as Biotherapeutics Agent"; in BioMed Research International Volume 2013, Article ID 620719.

Holzapfel, W.H.; Haberer, P.; Snel, J.; Schillinger, U.; Huis in't Veld, J.H.J. (1998) "Overview of Gut Flora and Probiotics", in International Journal of Food Microbiolology 41 (1998), pp. 85-101.

Jantzen, M.; Göpel, A.; Beermann, C. (2013) “Direct Spray Drying and Microencapsulation of Probiotic Lactobacillus Reuteri from Slurry Fermentation with Whey", in Journal of Applied Microbiology 115 (2013), pp. 1029-1036.

Kandler, O.; Stetter, K.; Kohl, R. (1980) "Lactobacillus reuteri sp. nov. A New Species of Heterofermentative lactobacilli", Zbl. Bakt. Hyg. Abt. Orig. C1 264-269.

Klein, G., Pack, A., Bonnaparte, C., Reuter, G. (1998) “Taxonomy and Physiology of Lactic Acid Bacteria", in International Journal of Food Microbiology 41 (1998), pp. 103-125. 
Markó, L. (2015) “Effect of Fluidized Bed Process Time on Survival Rate of Lactobacillus reuteri Probiotics Encapsulated with Sweet Whey and Shellac", Master Thesis, Corvinus University of Budapest, Department of Food Sciences, 2015.

Nagy, Á. Gy. (2015) “Improved Microencapsulation Process for Probiotics by Bottom Spray Fluidized Bed Granulation and Wurster Coating with Maltodextrin and Shellac", Master Thesis, University of Applied Sciences of Fulda, Faculty of Food Sciences, 2015.

Picot, A.; Lacroix, C. (2004) "Encapsulation of Bifidobacteria in Whey Protein-Based Microcapsules and Survival in Simulated Gastrointestinal Conditions and in Yoghurt"; in International Dairy Journal 14 (2004), pp. 505-515.

Reuter G. (1965) “Das Vorkommen von Laktobazillen in lebensmitteln und ihr Verhalten im menschlichen Intestinaltrakt". Zbl. Bak. Parasit. Infec. Hyg. I Orig. 197 (S): 468-87

Schell, D.; Beermann, C. (2014) "Fluidized bed microencapsulation of Lactobacillus reuteri with sweet whey and shellac for improved acid resistance and in-vitro gastro-intestinal survival", in Food Research International 62 (2014), pp. 308-314.

Szántó, V. (2013) "Verkapselung von Lactobacillus reuteri in Maltodextrin und Gummi arabicum mittels Sprüh- und Gefriertrocknung zur Verbesserung der Lagerstabilität", Master Thesis, University of Applied Sciences of Fulda, Faculty of Food Sciences, 2013.

Wassermann, M.; Weinholz, S.; Ivanova, N.; Cordes, C.; Peglow, M.; Pergande, W. (2011) "Granulation of Lactic Acid Bacteria Using Fluidized Bed Technology", 5th International Granulation Workshop, Lausanne, Switzerland, 2011. 